\title{
Review on Some Plants' Therapeutic Effects against Gastrointestinal Microbes
}

\author{
M. S. Abdallah ${ }^{1,2^{*}}$, R. Go $^{2^{*}}$, M. Mustafa $^{2}$ and M. Nallappan ${ }^{2}$ \\ ${ }^{1}$ Desert Research Monitoring and Control Centre, Yobe State University, Damaturu, Nigeria. \\ ${ }^{2}$ Department of Biology, Universiti Putra Malaysia, Serdang 43400, Selangor, Malaysia.
}

\begin{abstract}
Authors' contributions
This work was carried out in collaboration among all authors. Author MSA wrote the first draft of the manuscript. Author RG designed the study. Author MM managed the literatures. Author MN managed the literatures as well. All authors read and approved the final manuscript for publication.
\end{abstract}

Article Information

DOI: 10.9734/ARRB/2019/v31i630066

Editor(s):

(1) Dr. Paola Angelini, Department of Applied Biology, University of Perugia, Perugia, Italy. (2) Dr. Manikant Tripathi, Department of Microbiology, Dr. Ram Manohar Lohia Avadh University, India.

(3) Dr. George Perry, Dean and Professor of Biology, University of Texas at San Antonio, USA.

Reviewers:

(1) Mustafa Sevindik, Akdeniz University, Turkey. (2) Maria Demetriou, Metaxa Memorial Anticancer Hospital, Greece. (3) Uchendu, Mbah Okuwa, Michael Okpara University of Agriculture, Nigeria. (4) Oshim, Ifeanyi Onyema, Nnamdi Azikiwe University, Nigeria. Complete Peer review History: http://www.sdiarticle3.com/review-history/48480

Review Article

Received 25 February 2019

Accepted 08 May 2019

Published 15 May 2019

\section{ABSTRACT}

Plants play vital roles in many health care systems, be it rural or an urban community. Plants became familiar as medicine due to the primordial ideologies and believed. Several plant parts served as medicines to so many ailments including gastrointestinal ailments, due to the fact that their active ingredients are powerful against the microbes as well as healing so many physiological abnormalities. The principal antimicrobial components were used to inhibit the growth of microbes (S. aureus, E. coli, Salmonella spp, B. cereus, and B. subtili,), as well as most of the recognized compounds in most plants were aromatic or saturated organic compounds which enabled the plants to be active against the gastrointestinal microbes. The commonly used diluents were; water, methanol and Di methyl sulphate oxides to ascertain the level of activity of the plants. As such, plant materials in one way or the other are very active when dealing with microbes due to their active ingredients or the phytoconstituents. Most of the microbes identified in many reviewed 
researches were enteric bacterial species, by which divided into both gram negative and gram positive bacterial isolates, they differ in their cell components, which are the main targets of bioactive constituents to deal with any bacteria. However, certain parasites contributed towards the production of ailments for their survival and causing havoc to the hosts and sometimes be mutualistic.

Keywords: Ailments; compounds; gastrointestinal; microbes and plants.

\section{INTRODUCTION}

Plants served as good sources of medicines especially in developing as well as some of the developed countries, due to the facts that the orthodox are not assessable to the larger communities for immediate consumption to cure their ailments. Nowadays, some of the traditional beliefs are also being abandoned, which made some of the practices were abandoned [1,2]. Medicinal plant familiarity is like all local awareness, a community invention that is part of the specific traditional system. Local awareness is not always evenly distributed, and it is not every member of the group that is inescapably with the same facts [3].

Moreover, African traditional curative system and ethno medication have established appreciable consideration. The widespread literature on the issue which indicates clearly that traditional medication practice occupies a very protruding place in the treatment of diseases in the African culture. Traditional medicine is the sum total of consociate, facilities, and put on the reproductions, views, and practices home-based to different beliefs that are used to maintain health, as well as to avoid, identify, recover, or treat physical and psychological disorders. The management been employed by other populaces often termed consistent or auxiliary medicine [4]. Researches had shown that, there are a lot of local plants in Nigeria for the handling of numerous diseases. However, scientific facts have been known only on to a limited scope with few medicinal plants. But owing to the adverse effect of many orthodox drugs and the cost of obtaining these drugs. It is needful as a matter of fact to use plants which are natural reservoir of many antimicrobial agents as well as various healing activities $[5,6]$.

Consequently, about $80 \%$ of the developing nations relied on traditional medicines in treating many ailments and disorders as being reported by the World Health Organization (WHO) [4,7]. Herbalists prepared many parts of the plants such as stem, leaves and roots as orthodox due to their abundant constituents. Almost $90 \%$ of the population in some parts of Africa used herbal preparations for their primary healthcare as well as being propounded in developed countries like Germany and Canada tend to show that at least $70 \%$ of their population have tried at least once [8].

More so, Escherichia coli represents a very wider range on host, which derive benefit as well as serving as normal flora which par take in the pathogenesis so as to modulate host immunity. Different concentrations of the methanolic extracts of the leaves and barks of Psidium guajava, leaves of Mangifera indica and fruits and seeds of Carica papaya showed antimicrobial activities against all the isolates of bacteria ( $B$. cereus, $B$. subtilis, $E$. coli and Salmonella typhi) [9]. The antibacterial activity of organic extracts and essential oils of $P$. guajava leaves was also identified and revealed that methanolic extract has the highest zone of inhibition against shrimp isolates and type strains of S. aureus, E. coli and Salmonella spp as slated by [10]. S. paratyphi is Gram-negative, rod shaped, facultative anaerobe, non-encapsulated, non-spore forming, flagellated and motile bacteria. Three serotypes of $S$. paratyphi were described viz; S. paratyphi A, B and C worldwide. $S$. paratyphi transmission is through faecal oral route or via eating of unclean food/water as well as coming in contact with chronic asymptomatic carriers. The S. paratyphi caused enteric fever which is an important health issue in many developing countries [11].

Nevertheless, it is likely that the deep-thinking knowledge of herbal remedies in traditional cultures, advanced through trial and error over many periods, along with the most important cures was sensibly passed on orally from one generation to another. Indeed, modern medicine has its origins in the early medicine, and it is likely that many important new remedies will be developed and industrialized in the forthcoming from the African biodiversity, as it has been till now, by following the leads provided by traditional familiarity and experiences [4]. The 
main aim of this review is to ascertain the curative activities of different plants extracts on the gastrointestinal microbes.

\section{THE CONSUMPTION OF PLANTS AS MEDICINES}

The medicinal plants observed a myriad number of published works geared towards estimating the effectiveness from methodical proved in some part of the world, which are whispered to have an important support in the maintenance of well-being and in the introduction of new treatments. However, there is still a scarcity of updated wide-ranging compilation of good medicinal plants from the African continent [4]. Incorporation of traditional treatment in health systems since 1978, the WHO at its 31 st Assembly has suggested nations around the globe to make a complete record of medicinal plants, evaluation of their effectiveness, care and a standardization of the active products [8]. WHO has also reported some critical problems that hamper the incorporation of traditional medicine in the majority of countries; Public demands on common medicine exceeds the know-how and resources of health authorities; Inadequate guideline and registration for herbal products and other traditional treatments [8].

Nevertheless, the consumption of plants and their resources for treating different ailments have been proven by the olden day's literatures (Sumerian clay slab from Nagpur $\sim 5000$ years old) where by their usage are maintained up to today. While the isolation of some important compounds like morphine from opium started in the early 19th century, which were mainly at isolating active compounds from medicinal plants and as such, many compounds were also been discovered again. These product are later be used by many pharmaceutical companies and other developmental organizations [1].

More so, maximum number of medicinal plants is traditionally obtained from the wild, where they grow naturally. But as a result of many human activities, the floral communities become somehow disturbed. However, ( 15,000 medicinal plants) are at risk of becoming extinct due to over unnecessarily destruction. This activity is mostly found in the developing countries for the sake of their well-being which are also compounded to so many impacts which has been reported by [1].

Consequently, detailed deliberations with the informants and a cross-section of key informers among the traditional healers further exposed that even when the healers prescribe treatment to their patients, only the traditional doctor can prepare it; the patients are not well informed about the plant species from which the treatment is derived nor the method of preparation of the treatment. Even so, this system is slowly changing and in recent years, some flexibility seemed to be emerging, with the traditional healers and quite willing to provide information about the traditional treatments in exchange of financial benefits or compensation [12]. Lastly, today plants are considered in different uses varying from region to region and individuals to individuals. That is to say the use to which the same plant species can be put by the people in the riverine area may likely be different from those in the savannah and in certain restricted areas. Furthermore, man uses plant resources in many forms, the most basic are the following: food, medicine, cosmetics, architecture and for domestic facilities [13].

However, almost $30 \%$ scientific botanical data were mentioned to be the collated data showing the overall activities of medicinal plants in drugs production. Traditional medicine is somehow limited to local communities due to the lack of profound or broader knowledge on it. Phytochemical screenings of medicinal plants are very important in recognising new sources of medicinally and industrially vital compounds. It is also used to provide some of the products made by thee natural products [14]. Some of the plants products are often used in producing many antibiotics to treat bacterial and parasitic infections [14]. Today artemisinin based combination treatment is documented as drug of choice for handling malarial case, there are numerous advantages of herbal medicine which include; low-cost, affordability, prepared availability, convenience, adequacy and low harmfulness and are ready sources of medical power. However, many various disadvantages of the practices need to be resolved. Medicinal plants play spirited roles in disease prevention and their promotion and their usage in prevention strategies. Conscious efforts need to be made to properly recognise, distinguish and position medicinal plants in the design and implementation of these strategies [15].

Nevertheless, preparations were made by may diluents to extract the present plants need to be extracted, the natural products are screened based on the diluents used in the extraction procedures. In the crude extraction could be 
either in hot or cold water which worked differently. In most instances contents were not accurately measured [16]. Occasionally the patient used the aqueous extract for bathing the affected area. Where by some of the mixtures were used to support the extracts in treating the ailments in a good way, without ascertaining the right quantity of the mixtures administered [16]. Some years back, many researches have been carried out and documented in the late 19th century on medicinal plants by drawing a lot of attentions in myriad ways of applications. Therefore, many scientific findings have proved, many microbes are well treated based on the bioactive ingredients present in the plants extract [16].

\section{PLANTS THERAPEUTIC EFFECTS ON ORGANISMS}

Traditional medicine based on plants curative activity may increase and offer alternatives for animal disease control, particularly for resourcepoor breeders. In respect of this, many researches have been recommended to be carried out so as to know how to preserved the plants materials that will suit cultural heritage mankind utilization in many aspects in an entire African regions [17].

Consequently, the bacteria that colonize the gastrointestinal tract (GIT) achieved a number of functions which normalize and control the body of the host against the replication of microbes specifically the gastrointestinal ones [17]. Many factors triggered in the reduction of GIT bacteria and their beneficial functions due to their genetic composition to establish prime factors in the causation of diseases [17].

More so, Saponins are among the secondary metabolites mainly possessed by plants and in some lower animals and bacteria [18]. Saponins compounds are mostly, found in some parts of the plants; stems, leaves, tuber, seeds and in fruits which make them to be active in curing parasitic, fungal, bacterial infections and as well as insecticidal predator. In plants, saponins do also have a subclass of the large and chemically assorted group of phytoanticipin and phytoprotectant metabolites produced by plants [18]. Subsequently, most of the gastrointestinal microbes specifically bacteria served as gut micro flora which are linked with human diseases in such a way that caused infections. They partially depends upon the production of bioactive compounds such as short-chain fatty acids (SCFAs) and polyunsaturated fatty acids (PUFAs). These compounds served as by products which are vital to the maintenance of a healthy gut microbial community. Moreover, SCFAs and PUFAs play multiple dangerous roles in host defence and immunity, including anticancer, anti-inflammation, and anti-oxidant activities, as well as out-competition of enteric bacterial pathogens. Finally, advanced to the potential uses of these fatty acids with regards to food safety and human gut heal [19].

The ethno botanicals surveys of medicinal plants species, were important for consequent chemical and pharmacological bio prospections [20]. Moreover, the presence of several flavones and phenolic acids, which have radical scavenging properties, some of the compounds served were both found in the plants extract and the microbes; $P$. nigra, which play good role in protecting pinocembrin, pinostrobin and extracts from buds $P$. nigra and $P$. berolinensis against AgNPs induced inflammation and cytotoxicity in HGF-1 cells [21].

In addition, the $P$. berolinensis showed a very good activity, due to the presence of antioxidants in both the in vitro and bio autographic tests [21].

\section{DIVERSITY OF GASTROINTESTINAL SPECIES AND THEIR ACTIVITIES ON DIFFERENT PLANTS MATERIALS}

Escherichia coli represents a very wider range on host, which derive benefit as well as serving as normal flora as well as par take in the pathogenesis so as to modulate host immunity. A study has been carried out among the lower animals by describing how $E$. coli can be replicated and stimulate their responses [8]. In contrast to the immunoregulatory and protective effects of $E$. coli, other human commensal $E$. coli are hypothesized in the development of intestinal inflammation in Crohn's disease patients mostly [22].

More so, many plants having to be useful in treating a larger number of animal diseases where by some plants were selected to be for certain groups not and be effective. Plant species like; Passiflora foetida L., used for preventing poultry diseases, while Olax subscorpioidea Oliv. was also used for deworming dogs. The most common plants used by breeders were Cassiasieberiana DC., Khaya senegalensis (Ders) A. Juss, Diospyros mespiliformis Hochst. 
ex A. DC., Sterculia setigera Del, Bridelia ferruginea Benth, Guiera senegalensis $J$ Gmel., Opilia amantalea Roxb., Saba senegalensis (A. DC.) Pichon and Vitellaria paradoxa CF Gaertn. These plant species are more useful to delight gastroenteritis and skin diseases [22].

Moreover, the portal of administering these herbal medication were preparedly and essentially oral, followed by other ways which are also related to the one administering with recommended dose for the effectiveness of the extracts against a specific disease. A larger portion of plants species were used to address the ethno veterinary care in western region of Africa (Côte d'Ivoire) happened to useful [23]. However, these plants had been described for the treatment of other diseases. Only 5 species, namely; $M$. senegalensis, $M$. inermis, $K$. senegalensis, $V$. paradoxa and $A$. leiocarpus, had been reported for the same therapeutic indication in the previous ones, namely against diarrhoea and infection with intestinal worms. The later, traditional property has been linked to the auspicious anthelmintic activity of $K$. senegalensis $V$. paradoxa and $A$. leiocarpus. The survey revealed that the stem bark of $K$. senegalensis was used to treat a host of diseases. That observation is in full agreement with the statement of who recognized the great importance of $K$. senegalensis in traditional veterinary medicine in Africa. In Nigeria, this plant species one of the most common plants used for treatment of trypanasomiasis in domestic animals [23]. The three strains of the test organism ( $S$. aureus) were more liable towards Penicillin $g$ than the tea extract. Also, the restraint of the microorganisms by Pen. $g$. increased with increasing concentration of Pen $g$ [24].

On the other hand, increasing concentration of the tea extracts bring about in decreasing activity [24]. The active compounds in the crude extract acted synergistically in order to harness the differences the extracts and the normal antimicrobial drugs which all have the potentiality to act on the organisms causing the ailments or infections. Some of the principal antibacterial components of plants were suggested being polar compounds. While most of the identified components with antimicrobial activity extracted from plants were aromatic or saturated organic compounds which are more soluble in polar solvents such as water and methanol. However water extracts were less potent than others due to disparity in the outcomes of the activities [25].

Moreover, approximately five species of South African orchids were used to treat inflammatory conditions and other ailments. Polystachya ottoniana was used to soothe pain experienced in teething babies and to treat diarrhoea. Ansellia Africana is also administered as an antimicrobial while Eulophia species such as E. cucullata and $E$. ovalis, are used primarily to relieved pain. Investigation has shown that Cyrtochis arcuata treat diabetes and skin infections as well as Tridactyle tridentata treat psychological disorders such as madness. Two orchid species; $B$. scaberulum and $E$. hereroensis, used in South African traditional medicine were also included as they were being imported around the world. Orchid extracts that displayed significant effects in an anti-inflammatory, antioxidant and AChE inhibitory assays may have potential natural plant product targets in the treatment of inflammatory and neurodegenerative -tive disorders. Extracts include: $A$. africana, Et $\mathrm{OH}$ root, $B$. scaberulum DCM root, Cyrtochis. arcuata methanolic root, $E$. hereroensis DCM tuber, E. petersii DCM stem and $T$. tridentata DCM root extracts. The Et $\mathrm{OH}$ root extract of $B$. scaberulum exhibited the most potent selective inhibitory effect on COX-2, while the DCM tuber extract of E. hereroensis, was the only extract to significantly inhibit both COX enzymes as pin pointed by [26].

However, preliminary tests suggested significantly higher levels of Gallo tannin content in $A$. africana, and $E$. hereroensis methanol root extracts. Which showed the significant antiinflammatory activity. Similarly, the presence of condensed tannins in $E$. hereroensis root and and $B$. scaberulum stem/root extracts may explain the observed anti- inflammatory effects. The potent anti-inflammatory and antioxidant effect of $E$. hereroensis and $E$. petersii supported the use of species from this genus for inflammatory-related symptoms in South African traditional medicine which were also adopted in many part of the world. The overall \% ant of Prosopis pubescens pseudo bulb and root extracts was greater than $90 \%$, which might validate the use of species from this genus as substitutes to $P$. ottoniana, to treat certain inflammatory disorders. Flavonoids in the pseudo bulbs and roots of $P$. pubescens may have contributed to the antioxidant effects. Investigated leaf flavonoid content in Orchidaceae was highlighted by [26], as well as isolated xanthones, mangiferin and isomangiferin 
from five species of Polystachya and Maxillaria. The author also detected that there was no pattern of flavonoid distribution within the family Orchidaceae, and geographical location played a noteworthy role in the presence of flavonoid compounds. All four species recorded some flavonoid content in primary studies, shared similar sharing ranges; and are all epiphytic species for therapeutic effects. Plant compounds such as flavonoids, naphthoquinones, alkyl amides and phenolic phenyl-propane derivatives represented the usual compounds found in certain natural products that are responsible for COX inhibition [26]. The presence of flavonoids in $B$. scaberulum and $T$. tridentata may clarify the potent activity observed in the anti- inflammatory and AChE inhibitory assays. The medicinal value of flavonoids includes; anti-inflammatory, antifungal, antioxidant activities and wound healing. The wound healing efficacy of Oncidium flexuosum, an epiphytic orchid used in Brazilian traditional medicine for inflammation and wounds, was attributed to the presence of flavonoids and tannins [26]. Antibacterial pharmaceuticals are not accessible to the majority of the people who need them. The use of botanical medicines is generally on the rise in many parts of the world [27].

The antibacterial activity could be due to different classes of compounds. Some of the classes of compounds acknowledged in the crude extract, include; alkaloids and triterpenoids, have been reported to possessed antibacterial activity [27]. The increased occurrence of resistance to commonly used antibiotics has led to the search for newer, cheap, and easily cheap drugs in the management of infectious diseases. Although conventional drugs are popular, however, herbal medicine continued to be practiced due to richness of certain plants in varieties of secondary metabolites such as alkaloids, flavonoids, tannins, and terpenoids which have been stated to have antibacterial activities and other physiological roles played. Different studies showed different concentrations of the methanolic extracts of the leaves and barks of Psidium guajava, leaves of Mangifera indica and fruits and seeds of Carica papaya showed antimicrobial activities against all the isolates of bacteria (B. cereus, B. subtilis, E. coli and Salmonella typhi) [9].

The antibacterial activity of organic extracts and essential oils of $P$. guajava leaves was also examined, and the methanolic extract showed the highest inhibition against shrimp isolates and type strains of S. aureus, E. coli and Salmonella spp as slated by [10]. S. paratyphi is Gramnegative, rod shaped, facultative anaerobe, nonencapsulated, non-spore forming, flagellated and motile bacteria. Three serotypes of $S$. paratyphi were described; S. paratyphi A, B and C worldwide. S. paratyphi transmission is through faecal oral route or via eating of unclean food/water as well as coming in contact with chronic asymptomatic carriers. The S. paratyphi caused enteric fever which is an important health issue in many developing countries. The incidence is increasing globally particularly in endemic regions such as certain provinces in China and Pakistan. The disease mortality rate is up to 30 and $90 \%$ of deaths is due to enteric fever occur in Asia. Humans are the only reservoir and natural host for S. paratyphi. The $S$. paratyphi can be isolated from paratyphoid fever patients' blood for diagnosis. Paratyphoid fever is highest in teenagers and young adults as compared to typhoid fever that is common in children as being highlighted by [11].

Nevertheless, the DNA of some bacterial isolates that contributed towards gastrointestinal ailments were identified on different percentages using the DNA purification kit (Hiper Bacterial Genomic DNA Extraction Teaching Kit) [11]. Consequently, a very reasonable number affected with S. paratyphi and paratyphoid out of reasonable number of the samples collected. PCR based identification of specific gene used to sense S. Paratyphi. All isolates of S. paratyphi used to produce the specific size of 329 base pair fragment of flic-a gene as carried out by [11].

\section{GENOMES AND ETEC STRAINS PROFILE}

Research has shown that, ST ETEC strains were collected over a period of 31 years (1980-2011), across the globe so as to confirmed the strains of valuable importance [28]. The preliminary phytochemical components of methanolic and water extracts of $P$. guajava stem bark were identified in the different proportion to act on different species as well as strains of pathogenic importance as carried out by [10]. The results of the MIC and MBC on the MRSA isolates confirmed the activities of the extracts on the organisms [10].

\section{CONCLUSION}

The use of plants materials in treating different diseases has proven to many, are effective 
despite the facts that some of the users do not have a broader knowledge in the usage of the extracts as medicines due to the presence of bio constituents which make plants to be active, super active or less active. Many bacteria and parasites contributed towards the development of gastrointestinal ailments, which mostly identified in the diarrhoeal samples [29].

\section{COMPETING INTERESTS}

Authors have declared that no competing interests exist.

\section{REFERENCES}

1. Kankara SS, Ibrahim MH, Mustafa M, Go R. Ethnobotanical survey of medicinal plants used for traditional maternal healthcare in Katsina state, Nigeria. South African Journal of Botany. 2015;97:165175.

2. Sevindik $M$, Akgul $H$, Pehlivan $M$, Selamoglu Z. Determination of therapeutic potential of Mentha longifolia ssp. longifolia. Fresen Environ Bull. 2017;26: 4757-4763.

3. Ene AC, Atawodi SE. Ethnomedicinal survey of plants used by the Kanuris of North-Eastern Nigeria. Indian Journal of Traditional Knowledge. 2012;11(4):640645.

4. Mahomoodally MF. Traditional medicines in Africa: An appraisal of ten potent african medicinal plants. Evidence-Based Complementary and Alternative Medicine: ECAM. 2013;617459.

5. Madara AA, Abah RO, Elkanah OS. The revelator. Fudma Journal of Sciences. 2018;2. ISSN: 2616-1370

6. Mohammed FS, Akgul H, Sevindik M, Khaled BMT. Phenolic content and biological activities of Rhus coriaria var. zebaria. Fresen Environ Bull. 2018;27(8): 5694-5702.

7. Sevindik M. Investigation of antioxidant/ oxidant status and antimicrobial activities of Lentinus tigrinus. Advances in Pharmacological Sciences; 2018.

Available:https://doi.org/10.1155/2018/171 8025

8. Sawadogo WR, Schumacher $M$, Teiten $\mathrm{MH}$, Dicato M, Diederich M. Traditional West African pharmacopeia, plants and derived compounds for cancer therapy. Biochemical Pharmacology; 2012.
9. Tumpa SI, Hossain I, Ishika T. Papaya and mangifera indica against some gram positive and gram negative bacteria. Journal of Pharmacognosy and Phytochemistry. 2015;3(6):125-129.

10. Nneka NI, Anthony AA, Kwaliafon SM, Charles OE, Kennedy FC. Antimicrobial activity of Psidium guajava Linn. stem extracts against methicillin-resistant Staphylococcus aureus. African Journal of Biotechnology. 2016;11(89):15556-15559.

11. Panezai M, Taj MK, Nawaz I, Taj I, Panezai M, Panezai N, Muhammade G. Research article isolation and identification of salmonella paratyphi from enteric fever patients at different hospitals of quetta city. Pakistan Journal of Biological Sciences. 2018;21(9):469-474.

12. Mohammed S. Ethnobotanical survey of medicinal plants in metropolitan kan. Nigeria Ethnobotanical Survey of Medicinal Plants in. 2015;1-8.

13. Garba A. Useful plants in the Chad region of North-East Nigeria. L'homme et Le Milieu Végétal Dans Le Bassin Du Lac Tchad. 1997;113.

Available:http://books.google.com/books

14. Kumari P, Kumari C, Singh PS. Phytochemical screening of selected medicinal plants for secondary metabolites. Int. J. Life. Sci. Scienti. Res. 2017;3(4):1151-1157.

15. Elekwa I, Ugbogu A, Okereke S, Okezie E. A review of selected medicinal plants with potential health benefits in South-Eastern. International Journal of Pharmaceutical and Chemical Sciences. 2017;6(4):162171.

16. Ashidi JS, Houghton PJ, Hylands PJ, Efferth T. Ethnobotanical survey and cytotoxicity testing of plants of Southwestern Nigeria used to treat cancer, with isolation of cytotoxic constituents from Cajanus cajan Millsp. leaves. Journal of Ethnopharmacology. $\quad 2010 ; 128(2): 501-$ 512.

17. Vitetta L, Briskey D, Hayes E, Shing C, Peake J. A review of the pharmacobiotic regulation of gastrointestinal inflammation by probiotics, commensal bacteria and prebiotics. 20 Inflammopharmacology; 2012.

18. Walker MY, Pratap S, Southerland JH, Farmer-Dixon CM, Lakshmyya K, Gangula PR. Role of oral and gut microbiome in nitric oxide-mediated colon motility. Nitric Oxide. 2018;73:81-88. 
19. Peng $M$, Biswas D. Short chain and polyunsaturated fatty acids in host gut health and foodborne bacterial pathogen inhibition. Critical Reviews in Food Science and Nutrition. 2017;57(18):3987-4002.

20. Baldé AM, Traoré MS, Baldé MA, Barry MS, Diallo A, Camara $M$, Oularé $K$. Ethnomedical and ethnobotanical investigations on the response capacities of Guinean traditional health practioners in the management of outbreaks of infectious diseases: The case of the Ebola virus epidemic. Journal of Ethnopharmacology. 2016;182.

21. Pobłocka-Olech L, Inkielewicz-Stepniak I, Krauze-Baranowska M. Anti-inflammatory and antioxidative effects of the buds from different species of Populus in human gingival fibroblast cells: Role of bioflavanones. Phytomedicine. 2019;56:19.

22. Clavel T, Gomes-Neto JC, Lagkouvardos I, Ramer-Tait $A E$. Deciphering interactions between the gut microbiota and the immune system via microbial cultivation and minimal microbiomes. Immunological Reviews. 2017;279(1):8-22.

23. Koné WM, Kamanzi Atindehou K. Ethnobotanical inventory of medicinal plants used in traditional veterinary medicine in Northern Côte d'Ivoire (West Africa). South African Journal of Botany; 2008.
24. Esimone CO, Iroha Ibezim EC, Okeh CO, Okpana EM. In vitro evaluation of the interaction between tea extracts and Penicillin g. against Staphylococcus aureus. African Journal of Biotechnology. 2006;5(11):1082-1086.

25. Mushore J, Matuvhunye M. Antibacterial properties of Mangifera indica on Staphylococcus aureus. African Journal of Clinical and Experimental Microbiology. 2013;14(2).

26. Chinsamy M, Finnie JF, Van Staden J. Anti-inflammatory, antioxidant, anticholinesterase activity and mutagenicity of South African medicinal orchids. South African Journal of Botany. 2014;91:88-98.

27. Bbosa GS, Kyegombe DB, Ogwal-Okeng J, Bukenya-Ziraba R, Odyek O, Waako P. Antibacterial activity of Mangifera indica (L.).

Available:https://onlinelibrary.wiley.com

28. Joffré $E$, von Mentzer A, Svennerholm AM, Sjöling Å. Identification of new heat-stable (STa) enterotoxin allele variants produced by human enterotoxigenic Escherichia coli (ETEC). International Journal of Medical Microbiology. 2016;306(7):586-594.

29. Gotep JG, Lohlum AS, Makama S, Elisha IL, Makoshi MS, Offiah NV, Oladipo OO. Ethnobotanical survey of medicinal plants used in the treatment of animal diarrhoea in Plateau State, Nigeria. BMC Veterinary Research. 2011;7(1):36.

(c) 2019 Abdallah et al.; This is an Open Access article distributed under the terms of the Creative Commons Attribution License (http://creativecommons.org/licenses/by/4.0), which permits unrestricted use, distribution, and reproduction in any medium, provided the original work is properly cited.

Peer-review history:

The peer review history for this paper can be accessed here: http://www.sdiarticle3.com/review-history/48480 